\title{
O CONTEXTO DA CONSOLIDAÇÃO DAS AVALIAÇÕES EM LARGA ESCALA NO CENÁRIO BRASILEIRO*
}

\author{
IANa Gomes De Lima ${ }^{1}$ (1) \\ Luís Armando GANDin ${ }^{2}$ (1)
}

\begin{abstract}
RESUMO: Neste artigo, tem-se como objetivo examinar como as avaliaçóes em larga escala têm se consolidado no Brasil conforme o cenário global. Defende-se que, apesar de haver repercussóes nacionais dos organismos internacionais de fomento de políticas educacionais rumo às avaliaçóes padronizadas, elas precisam ser entendidas sob a perspectiva das rearticulações locais e da consolidação da hegemonia no Brasil. Para tanto, faz-se uso, centralmente, dos conceitos de hegemonia e articulação com base nos estudos de Stuart Hall e de Michael Apple. A metodologia da pesquisa inclui a realizaçáo de entrevistas realistas com importantes formuladores de políticas do cenário brasileiro e análise de documentos oficiais significativos. Conclui-se que o processo que levou à consolidação das avaliaçóes em larga escala no Brasil tem dois elementos centrais. $\mathrm{O}$ primeiro é a proliferação de discursos hegemônicos e de práticas concretas, no âmbito global, que afirmam a importância das avaliaçóes de larga escala. $\mathrm{O}$ segundo refere-se a uma articulação que compreende, no que compete às avaliaçôes, uma demanda internacional que é colocada lado a lado às particularidades do Brasil, o que culmina na consolidação do Sistema de Avaliação da Educação Básica e das avaliaçóes em larga escala como práticas do contexto brasileiro.
\end{abstract}

Palavras-chave: Avaliaçóes em larga escala. Estado brasileiro. Políticas educacionais. Hegemonia. Articulação.

\section{THE CONTEXT OF THE CONSOLIDATION OF LARGE-SCALE EVALUATIONS IN THE BRAZILIAN SCENARIO}

ABSTRACT: In this article, we aim at examining how large-scale evaluations have been consolidated in Brazil, taking into account the

\footnotetext{
*Este artigo foi desenvolvido por meio do projeto de pesquisa intitulado As ações do Estado brasileiro na educação básica: uma análise a partir do Sistema de Avaliação da Educação Básica, financiado pelo Conselho Nacional de Desenvolvimento Científico e Tecnológico (CNPq).

${ }^{1}$ Universidade Federal do Rio Grande do Sul, Faculdade de Educação - Porto Alegre (RS), Brasil.

E-mail: iana_glima@yahoo.com.br

${ }^{2}$ Universidade Federal do Rio Grande do Sul, Programa de Pós-Graduação em Educação - Porto

Alegre (RS), Brasil. E-mail: luis.gandin@ufrgs.br

DOI: 10.1590/ES0101-73302019204183
} 
global scenario. We argue that, although there are repercussions from the international funding agencies to national standardized assessments, they need to be understood from the local rearticulations and from the consolidation of the Brazilian hegemony. The concepts of hegemony and articulation are used, centrally, in the studies of Stuart Hall and Michael Apple and help us examine the Brazilian context. The methodology of this research include realistic interviews with important policy makers and the analysis of significant official documents. We conclude that the process that led to the consolidation of large-scale evaluations in Brazil presents two central elements. The first is the proliferation of hegemonic discourses and concrete practices at the global level that affirm the importance of evaluations. The second refers to a link, in the Brazilian scenario, between the understanding of international assessments and Brazilian particularities, which culminated in the consolidation of the Basic Education Assessment System and the large-scale evaluations as practices in the Brazilian context.

Keywords: Large-scale evaluation. Brazilian State. Educational policies. Hegemony. Articulation.

\section{EL CONTEXTO DE LA CONSOLIDACIÓN DE LAS EVALUACIONES EN LARGA ESCALA EN EL ESCENARIO BRASILEÑO}

RESUMEN: En este artículo, se tiene como objetivo examinar cómo las evaluaciones en larga escala se han consolidado en Brasil según el escenario global. Se defiende que, a pesar de haber repercusiones nacionales de los organismos internacionales de fomento de políticas educacionales rumbo a las evaluaciones estandarizadas, ellas necesitan ser entendidas a partir de las rearticulaciones locales y de la consolidación de la hegemonía en Brasil. Para tal, se hace uso, centralmente, de los conceptos de hegemonía y articulación con base en los estudios de Stuart Hall y de Michael Apple. La metodología de la investigación incluye la realización de entrevistas realistas con importantes formuladores de políticas del escenario brasileño y análisis de documentos oficiales significativos. Se concluye que el proceso que llevó a la consolidación de las evaluaciones en larga escala en Brasil tiene dos elementos centrales. El primero es la proliferación de discursos hegemónicos y de prácticas concretas, en el ámbito global, que afirman la importancia de las evaluaciones de larga escala. El segundo se refiere a una articulación que comprende, en lo que compete a las evaluaciones, una demanda internacional que es colocada lado a lado a las particularidades de Brasil, lo que culmina en la consolidación del Sistema de Evaluación de la Educación Básica y de las evaluaciones en larga escala como prácticas del contexto brasileño.

Palabras clave: Evaluaciones en larga escala. Estado brasileño. Políticas educacionales. Hegemonía. Articulación. 


\section{Introdução}

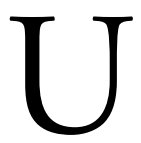

sando os conceitos hegemonia e articulação, examinamos como as avaliaçóes em larga escala têm se consolidado no Brasil, conforme um cenário global. Tratamos de demonstrar que, apesar de haver repercussões nacionais dos organismos internacionais de fomento de políticas educacionais rumo à avaliaçóes padronizadas, elas precisam ser entendidas mediante as rearticulaçôes locais e a consolidação da hegemonia no Brasil. Para isso, trazemos a palavra de atores centrais na construção das políticas educacionais brasileiras, bem como de atores que circulam em torno da definição dessas políticas.

Este artigo está baseado em uma pesquisa mais ampla realizada para verificar, a partir do Sistema de Avaliação da Educação Básica, as ações do Estado brasileiro na educação básica no período de 1995 a 2014. Os dados apresentados neste texto são analisados, nesse momento, pelo foco referido. A metodologia da pesquisa inclui a realização de entrevistas realistas ${ }^{1}$ (PAWSON; TILLEY, 2000) com importantes formuladores de políticas (ex-ministros da Educação e membros de suas equipes, ex-presidentes do Instituto Nacional de Estudos e Pesquisas Educacionais Anísio Teixeira - INEP, atores de organizaçóes não estatais, membros de organizaçôes internacionais), entendendo que, atualmente, não somente atores estatais, mas também não estatais, têm se feito presentes na construção de políticas educacionais no Brasil. Além das entrevistas, foram analisados documentos oficiais significativos do período em questão, tais como leis, o Plano Diretor da Reforma do Aparelho do Estado (BRASIL, 1995) e o II Plano Nacional de Educação (BRASIL, 2014).

Neste artigo, defendemos que as avaliaçóes em larga escala têm sido "naturalizadas" e firmadas, no cenário brasileiro, como uma prática necessária. É possível verificar por meio de documentos, do aprimoramento e da criaçáo de testes nos últimos anos e das falas de entrevistados que reproduzimos aqui que o uso de avaliaçóes em larga escala é tomado como um dado, não sendo cogitado pensar que elas possam não existir. $\mathrm{O}$ processo que levou ao estabelecimento dessa naturalização e consolidação teve, como indica este artigo, dois elementos centrais:

- a proliferação de discursos hegemônicos e de práticas concretas, no âmbito global, que afirmavam a importância das avaliaçôes;

- uma articulação, no cenário brasileiro, na qual se constata um compromisso entre as avaliaçôes internacionais e as particularidades do Brasil, o que culminou na solidificação do Sistema de Avaliação da Educação Básica (SAEB) e das avaliaçóes em larga escala como práticas do contexto brasileiro.

Detemo-nos, agora, nessas duas questōes. 


\section{Âmbito global: proliferação de discursos hegemônicos e de práticas concretas sobre a importância das avaliações em larga escala}

Estudos (BONAMINO; FRANCO, 1999; COELHO, 2008; SANTOS, 2007) demonstram que o nascimento do SAEB, no fim da década de 1980, e sua ampla reestruturaçáo, no ano de 1995, foram influenciados pelos organismos internacionais. No levantamento dos dados que dáo base a este artigo, buscamos compreender se a influência documentada dos anos de 1990 (FONSECA, 1998; 2001; HADDAD, 2008) era também percebida e se fez presente depois dessa década. Para tanto, analisamos documentos e entrevistas com alguns importantes formuladores de políticas - que serão destacados ao longo deste texto. Os entrevistados apontaram que, mesmo que essa influência tenha existido, em determinado grau ela é distinta daquela presente nos anos 1990. Identificamos que a influência passou a ser diferente em função da modificação, ao longo dos anos, do posicionamento do Brasil perante os organismos internacionais, o que deriva, especialmente, de seu lugar econômico no cenário mundial. Isso fez com que a relação entre organismos internacionais e o Estado brasileiro fosse divergente, pois, à medida que o Brasil reduziu drasticamente a necessidade de realizar empréstimos para a área da educação, houve menos cobranças no que tange ao cumprimento de exigências por parte dos organismos internacionais. No entanto, como será tratado no decorrer desta seçấo, não se pode esquecer que o Estado brasileiro apresentou continuidade no que se refere aos processos avaliativos. Portanto, a mencionada pressão menor dos organismos internacionais no cenário brasileiro também ocorreu pelo fato de as avaliaçôes já estarem consolidadas no país.

Um exemplo das exigências feitas pelos organismos internacionais quando da realizaçáo de empréstimos pode ser vista no desenvolvimento inicial do SAEB. Cláudia Costin, que no momento da entrevista era diretora global de educação do Banco Mundial (tendo assumido o cargo em julho de 2014 e permanecido nele até junho de 2016), e Maria Helena Guimarães de Castro, que no momento da entrevista não tinha cargo federal (foi presidente do INEP entre 1995 e 2001, secretária executiva do Ministério da Educação em 2002 e novamente secretária executiva do Ministério da Educação entre 2016 e 2018, tendo se afastado em maio de 2018), afirmaram, em suas entrevistas, que o Banco Mundial desempenhou um papel específico na definição de políticas educacionais. Segundo Maria Helena Guimarães de Castro (2015):

É verdade que o Banco Mundial, no final dos anos [19]80, ofereceu um grant ${ }^{2}$ ao Ministério da Educaçáo e esse grant estava direcionado para o Projeto Nordeste, o antigo [Programa de Expansão e Melhoria da Educação no Meio Rural] Edurural, o 
Projeto Nordeste tinha por objetivo melhorar a gestão educacional da regiáo do nordeste brasileiro e esse grant, que era muito grande - eram 750 milhóes de dólares - tinha um componente nacional. E o componente nacional era a criação de um sistema nacional de avaliação em larga escala. De um sistema de avaliação da educação básica em larga escala e que, depois, virou o SAEB. Bom, naquela época, o Banco Mundial tinha várias iniciativas em vários países da América Latina. Por exemplo, o Sistema de Avaliação do Chile, o do México, o da Colômbia, o do Peru. Todos os países...

$\mathrm{Na}$ fala exibida, pode-se perceber que o Banco Mundial — assim como demonstra a literatura (BONAMINO; FRANCO, 1999; COELHO, 2008; SANTOS, 2007) - exerceu papel importante para a criação do SAEB. No entanto, apesar do apoio financeiro, Maria Helena Guimarães de Castro destacou que a instituiçãa não teve influência quanto à metodologia ou ao marco teórico-metodológico dos sistemas de avaliação nos diferentes países. Castro afirma que houve incentivo do Banco Mundial especialmente no que se refere ao financiamento do sistema. A ex-presidente do INEP relatou que acompanhou de perto o desenvolvimento de sistemas avaliativos no Brasil, Chile, Argentina, México e Colômbia e, portanto, pode afirmar que, nesses casos, "o Banco Mundial não tinha interesse no desenho do sistema de avaliação e nem nos aspectos conceituais, tanto é que cada um desses países tem um sistema diferente do outro" (CASTRO, 2015). É importante notar, porém, que não ter uma proposta fechada de modelo avaliativo para cada país deixa de enfatizar a pressão exercida pela existência de algum modelo de avaliação em larga escala, como vai ficar claro na discussão que oferecemos na sequência.

Fonseca (2001) traz importantes contribuiçóes para o entendimento do papel do Banco Mundial nos países em desenvolvimento. A autora afirma que o referido banco, assim como muitas outras agências de fomento à educação, submete seus financiamentos às chamadas condicionalidades. De acordo com Fonseca (2001), nos anos de 1980, o Banco Mundial realizou uma reestruturação no seu sistema de créditos, que passou a ter um novo modelo de empréstimo no qual o banco deixou de realizar um acompanhamento rigoroso dos projetos de financiamento e passou a participar de maneira mais ativa da definição de agendas dos setores financiados. Fonseca (2001) ainda afirma que o Banco Mundial definiu um conjunto de políticas fundamentais para a concessão de créditos no âmbito educacional, sendo uma das tendências a "vinculação dos objetivos educacionais à política econômica do Banco, no que se refere ao papel da educação para a inserção diferenciada no mercado de trabalho" (FONSECA, 2001, p. 91). Maria Helena Guimarães de Castro resume o papel do Banco Mundial da seguinte forma: 
Então, eu acho importante separar: o Banco Mundial influenciou a criaçáo muito mais com incentivos à criaçáo de sistemas de avaliação, apostando recursos para a implantação desses sistemas, muitas vezes, até, financiando a vinda, a realização de seminários, vinda de especialistas internacionais de diferentes países, mas, que eu saiba, ele náo teve influência no desenho do sistema e da metodologia, porque cada país fez do seu jeito, portanto, a autonomia de cada país foi garantida (CASTRO, 2015).

Da fala, destacamos dois aspectos. O primeiro deles é que, quando Castro afirma que o Banco Mundial muitas vezes financia a vinda de especialistas, não pode ser entendido que ele tenha apenas o papel de financiador das políticas, mas também de formador. Esses especialistas são o que Silva, Azzi e Bock (2008) denominam de assistência técnica oferecida pela instituição, e os diversos especialistas que estão a serviço do Banco Mundial "constituem uma 'rede gerencial' no interior da máquina administrativa de cada país para verificar a execução dos projetos" (SILVA; AZZI; BOCK, 2008, p. 27). Os autores chamam a atenção para o fato de especialistas do Banco Mundial, para além da consultoria específica para determinada temática, também influenciarem mudanças mais gerais no Estado, já que estão identificados com os pressupostos gerenciais.

O segundo aspecto é que os organismos internacionais desempenham diferentes papéis em relação às políticas de avaliação em cada país e que no Brasil esse papel teria sido de investidor financeiro. Todavia, cabe ressaltar que a cooperaçáo do Banco Mundial à educação no Brasil "ultrapassou o limite da assistência técnica e financeira propriamente ditas, tendo propiciado a participação internacional na definição de políticas educacionais” (FONSECA, 2001, p. 95). Tal é o caso, por exemplo, do próprio SAEB, que teve sua criação vinculada a uma condicionalidade do banco, que exigia a criação de um sistema nacional de avaliação para que o empréstimo destinado ao Projeto Nordeste fosse efetivado. Logo, mesmo que o Brasil tenha tido certa autonomia para o desenho dessa política, não se pode afirmar que o banco tenha exercido apenas o papel de órgão financeiro. A ideia trazida por Maria Helena Guimarães de Castro de que o apoio do Banco Mundial foi muito mais significativo no campo financeiro é diferente daquela desenvolvida por Sérgio Haddad (2008, p. 5), que afirma que a grande influência do Banco Mundial no Brasil "decorre menos do volume de recursos financeiros mobilizados pelos projetos e mais pela influência junto aos governos por meio da imposição de temáticas prioritárias e de uma abordagem economicista das políticas educacionais".

Cláudia Costin, ex-diretora global de educação do Banco Mundial, em sua entrevista, afirmou que o Fundo Monetário Internacional (FMI) não teve nenhum tipo de relação com o Saeb, apontando que há grande confusão quanto ao papel dos organismos internacionais. No entanto Fonseca (1998) afirma que, 
desde a década de 1970, o Banco Mundial atua com o FMI no sentido de conduzir os ajustes estruturais para a reforma dos Estados em direção ao globalismo econômico e como "articulador da relaçáo econômica entre os países do terceiro mundo, inclusive no que tange à negociação da dívida externa e à abertura comercial exigida no processo de globalização" (FONSECA, 1998, p. 38). Assim, mesmo que seja o Banco Mundial aquele que realiza empréstimos de forma mais direta para a área da educação, o FMI está também associado ao Banco Mundial, principalmente por meio do estabelecimento de uma pauta sobre as mudanças estatais necessárias em cada país, rumo a um crescimento econômico e ao processo de globalização, o que afeta igualmente as políticas educacionais.

Haddad (2008) afirma que o FMI atua juntamente com o Banco Mundial e com outras instituiçóes como o Banco Interamericano de Desenvolvimento (BID), sendo o primeiro o grande moldador das políticas econômicas e as outras organizaçóes encarregadas de pautar políticas públicas. Haddad (2008, p. 8) ainda assegura que o FMI "é o pilar do sistema financeiro internacional". As condicionalidades para os empréstimos são, geralmente, cruzadas entre as diversas agências internacionais "de maneira que as ações de todas estejam comprometidas com a mesma lógica de governança econômica global, que, em geral, são coordenadas e dominadas pelos interesses dos países mais fortes" (HADDAD, 2008, p. 9). $\mathrm{O}$ autor explica que "os mecanismos de influência do [Banco Mundial] BM chegavam às orientaçóes das políticas educacionais sempre em complementaridade às orientaçóes macroeconômicas estabelecidas pelo Brasil nos seus acordos com o FMI" (HADDAD, 2008, p. 11). Haddad (2008) exemplifica esclarecendo que, quando as orientaçóes macroeconômicas do FMI determinavam cortes de despesa, o Banco Mundial orientava, na área educacional, focar os recursos no ensino fundamental, preocupando-se mais com a eficácia do sistema do que com o aumento dos gastos, operando, assim, na lógica do custo $\times$ benefício. Ademais, o fato de que os países-membros do banco precisam ser também membros do FMI mostra a integraçáo entre esses dois organismos.

O que se depreende das formulaçóes de Fonseca (1998) e Haddad (2008) é que, mesmo que o FMI não seja diretamente o financiador das políticas educacionais, as decisóes desse organismo também trazem reflexos para o âmbito educacional de cada país. Tendo em vista os acordos firmados durante as gestóes de Fernando Henrique Cardoso com o FMI, é possível apreender que houve, no cenário brasileiro, as chamadas "condicionalidades cruzadas" (HADDAD, 2008) entre as orientaçóes do FMI para a economia macro e as do Banco Mundial para a área educacional. Portanto, a fala de Cláudia Costin ao afirmar que o "FMI não tem nenhum tipo de relação com o SAEB" não se sustenta, pois, conforme o que é apontado na literatura, o FMI teve, sim, relação indireta, já que nos anos de 1990, quando o SAEB foi fortalecido e expandido, empréstimos foram realizados e, assim, o Brasil teve de cumprir condicionalidades que também influenciaram a área educacional. De forma possivelmente mais forte ainda, a influência indireta 
desses dois órgãos deu-se via estabelecimento de um entendimento hegemônico a respeito da necessidade da existência de modelos nacionais de avaliação em grande escala.

Tarso Genro, ex-ministro da Educação em 2004 e 2005, durante o primeiro mandado do presidente Luiz Inácio Lula da Silva, ao responder, na sua entrevista, a uma questáo sobre o posicionamento do Brasil no que diz respeito aos organismos internacionais, propôs uma análise da relação entre os Estados nacionais e a economia financeira global. Segundo Genro, existem três ordens de influência do capital financeiro no tocante aos Estados nacionais:

- a interpretação das normas constitucionais;

- a produção legislativa;

- $\quad$ as decisões políticas que os governantes fazem.

Nesse terceiro ponto, o ex-ministro destaca que existem duas vertentes bem definidas: abdicação de qualquer resquício de soberania popular e cumprimento das normativas que vêm do capital financeiro sobre o Estado, ou busca de uma saída fora dessa submissão. No entanto a saída dessa submissão é bastante estreita, pois, segundo Genro (2015):

É impossível você se libertar dessa tutela se você não tem uma logística financeira, uma logística material, produtiva, capaz de criar um processo nacional desenvolvimentista fora de uma relação com a economia global. Então, a grande utopia democrática passou a ser, depois dessa financeirizaçáo geral da economia de domínio dela sobre o Estado, resistir a essa visão de submissão e de abdicação da soberania e estabelecer um projeto de cooperaçáo interdependente, que é a grande utopia democrática hoje. A grande utopia democrática não é dizer: "Bem, o capital financeiro não vai ter influência sobre o Estado". Vai ter, queira ou náo queira. Se trata como estabelecer uma comunicação dessa ordem financeira global de modo que você possa exercer a soberania em um regime de cooperação e não em um regime de submissão.

Na leitura de Genro (2015), o exercício da soberania foi uma importante conquista dos governos do presidente Luiz Inácio Lula da Silva, pois houve o estabelecimento de uma relação muito mais de cooperação interdependente do que de submissão. Para exemplificar essa cooperação interdependente, Genro (2015) aponta que foram elaboradas, durante os governos do presidente Lula, políticas que se opunham à tutela das agências internacionais, como é o caso, segundo ele, da expansão das universidades federais, "capilarizando o território com bom ensino superior", contudo o ex-ministro afirma que, no próprio governo, havia 
pessoas contrárias a tal expansão. Isso, de acordo com Genro (2015), demonstra a "contradição permanente que qualquer governo enfrenta". Para o ex-ministro, a relaçáo de cooperação interdependente permitiu que o Brasil tivesse outra relação com os organismos internacionais financeiros.

Pode-se interpretar pela fala de Genro (2015) que, anteriormente ao governo Lula, havia uma política de submissão do governo brasileiro às normas do que determinava, por exemplo, o Banco Mundial, ao realizar um empréstimo. O discurso sobre a não submissão do Brasil aos organismos internacionais foi uma das plataformas de Luiz Inácio Lula da Silva na campanha presidencial de 2002, quando falava do pagamento da dívida externa que o Brasil tinha com o FMI, o que faria com que o Estado brasileiro não dependesse mais de tais organismos. Tude e Milani (2013) afirmam que, mesmo que no começo de 2003, início do primeiro mandato do presidente Lula, as relaçóes do governo com o FMI tenham sido baseadas no respeito aos acordos estabelecidos e na política de não confrontação, em setembro do mesmo ano foi possível perceber o desejo do presidente Lula em diminuir as relaçóes de proximidade com o FMI. Em uma entrevista concedida a Emir Sader e Pablo Gentili (2013), Lula explica que não desejava ter nenhuma dívida com a organização, o que justifica, segundo o ex-presidente, o ajuste fiscal que foi feito em 2004 e que possibilitou que no ano seguinte o presidente devolvesse o dinheiro do empréstimo para o FMI e, um ano e meio depois, o Brasil contasse com quase 100 bilhóes de dólares de reservas.

Quanto ao pagamento da dívida ao FMI, Tude e Milani (2013) afirmam que, em 2005, foram pagos ao fundo, de maneira antecipada, cerca de 15 bilhóes de dólares, referentes aos empréstimos que haviam sido tomados. Naquela época, o Ministério da Fazenda justificou que o pagamento ao FMI "ampliou a autonomia do Brasil na gestão de suas políticas macroeconômicas e maximizou sua confiança internacional, fortalecendo o mercado de capitais pátrio e diminuindo o risco-país" (TUDE; MILANI, 2013, p. 91). De acordo com Tude e Milani (2013), no início de 2005, Luiz Inácio anunciou que não faria a renovação dos acordos com o fundo, o que para alguns especialistas fazia sentido, "na medida em que o País já não se encontrava mais em crise, estava obtendo superávits nas transaçóes correntes e havia reduzido de maneira consistente sua vulnerabilidade externa” (TUDE; MILANI, 2013, p. 90).

O fato de o Brasil contar com reservas próprias propiciou outro tipo de relacionamento com organismos internacionais como o Banco Mundial e o FMI, que costumavam realizar empréstimos para o desenvolvimento de políticas educacionais brasileiras. Ademais, conforme destaca Pochmann (2013), depois da crise global de 2008, China, Índia e Brasil foram responsáveis por promover parte substancial da expansão econômica mundial, algo que atesta que o Brasil passou a ocupar, naquele momento, importante posição na economia mundial. Em 16 de 
janeiro de 2006, Luiz Inácio Lula da Silva realizou um pronunciamento à nação em cadeia de rádio e TV que apontou a importância do pagamento da dívida ao FMI:

Meus amigos e minhas amigas, há poucos dias o Brasil zerou a sua dívida com o FMI. Com isso, deixamos de pagar juros, e com essa economia vamos poder investir mais em favor do nosso povo. Com soberania viramos uma página da nossa história. O Brasil vai caminhar com suas próprias pernas. Ao devolvermos ao FMI o dinheiro que estava à disposiçáo do Brasil por conta da crise de 2001-2002 estávamos provando, dentre outras coisas, que não dependemos mais de empréstimos externos para continuar crescendo, podemos fazê-lo com nossos próprios recursos (SILVA, 2006).

No trecho apresentado - a abertura do pronunciamento de Lula - , é possível verificar alguns pontos importantes:

- a afirmação de que, ao pagar a dívida com o FMI, seria possível investir mais em "nosso povo";

- $\quad$ a ideia de que, a partir daquele momento, "o Brasil vai caminhar com suas próprias pernas";

- $\quad$ a noção de não dependência de empréstimos externos e de soberania do país.

Essas questóes apontam a frequência, no governo Lula, da veiculação de um discurso sobre a possibilidade de o Brasil poder ser um país soberano, independente financeiramente, o que pode auxiliar a entender essa ideia salientada pelos entrevistados de que o Brasil não é mais influenciado pelos organismos internacionais. Segundo Tude e Milani (2013, p. 99):

Ao longo de todo o segundo mandato, a mensagem passada repetidamente à população brasileira era de que o FMI não mais exerceria controle político sobre o Brasil, mas sim o Brasil passaria a exercer maior influência nas dinâmicas institucionais e financeiras do Fundo.

Pilar Lacerda ${ }^{3}$, ex-secretária da Secretaria de Educação Básica (SEB) do Ministério da Educação (MEC) no período de 2007 a 2012, tendo atuado, portanto, no segundo mandato do presidente Luiz Inácio Lula da Silva e no primeiro mandato da presidenta Dilma Rousseff, reforça a ideia de não dependência desses organismos: "A participação dos organismos internacionais no Ministério, a partir do Governo Lula, muda muito" (LACERDA, 2015). De acordo com a ex-secretária, isso ocorreu porque o Brasil não desejava mais receber empréstimos do Banco Mundial, no entanto ela afirma que instituiçóes como essas "precisam 
aportar esse dinheiro, então, eles procuram muito mais do que são procurados" (LACERDA, 2015). Segundo o que diz Lacerda, tal cenário mudou porque o Brasil estava "em uma onda boa de economia" e, também, pelo fato de que, a partir de 2005, houve aprofundamento na área de avaliação, pois se entendia que "essas avaliaçóes são importantes para a política externa" (LACERDA, 2015). Além desses fatores, a ex-secretária da SEB traz em sua fala um argumento que se assemelha ao que Genro chama de regime de cooperação. Conforme o que diz Lacerda (2015):

Se precisar de recurso externo, é preciso manter a nossa [referindo-se ao Brasil] soberania, ou seja, eu estou te pedindo um dinheiro emprestado, eu vou pagar, mas eu não vou vincular a fazer A, B ou C. Essa mudança, que é uma questáo de soberania, ela é muito sentida dentro do Ministério. Isso para mim foi a diferença maior.

Pochmann (2013), ao fazer uma análise dos dez primeiros anos dos governos Lula e Dilma, corrobora o que é apontado por Genro e Lacerda no tocante ao posicionamento do Brasil perante os organismos internacionais. $\mathrm{O}$ autor ressalva que de 2003 a 2013 o país equacionou alguns dos problemas de vulnerabilidade externa, passando de devedor a credor dos organismos internacionais e multiplicando por dez vezes a soma das reservas externas. Pochmann (2013, p. 156) destaca ainda que, no que concerne aos organismos internacionais, "o país vem exercendo cada vez mais uma posição de liderança até então desconhecida, o que fez da economia externa brasileira uma referência galvanizadora do protagonismo soberano e integrador de cooperação técnica crescente com outras nações”. Assim como Genro e Lacerda, Pochmann (2013) faz uso do termo soberano, sugerindo que o Brasil passou a ocupar posição diferente no cenário mundial. Cunha (2016) ratifica a ideia de que o país passava por um momento econômico positivo ao afirmar que, no período em que Fernando Haddad e Henrique Paim foram ministros da Educação, ou seja, entre 2005 e 2015, ambos "tiveram a sabedoria de aproveitar uma boa fase da economia do País para fortalecer o ministério, em termos de política de educação e de orçamento" (CUNHA, 2016, p. 447). O que se pode depreender dessa afirmação de Cunha (2016) é que a boa fase econômica do Brasil também perpassou pelo próprio MEC.

Os consultores da Câmara dos Deputados na área de Educação, Cultura e Desporto Ana Valeska Amaral Gomes, que trabalha desde 2005 como consultora legislativa na área, e Paulo de Sena, que desde 1994 também atua como consultor legislativo na mesma área, corroboraram essa ideia ao assegurarem perceber que, nos anos 1990, as políticas de avaliação eram mais diretamente pautadas pelos organismos internacionais (GOMES, 2015; SENA, 2015). Ana Valeska trabalhou no MEC no ano de 1997 e contou que, nessa época, notava influência maior de tais organismos. Para a consultora, essa influência mais direta também estava rela- 
cionada com o fato de que as políticas de avaliação se disseminavam pelo mundo na década de 1990 e, portanto, os organismos internacionais precisavam trazer a avaliaçáo à cena, tratando de "convencer" os países a realizar políticas de avaliaçáo. Esse processo de convencimento pode ser entendido por intermédio do conceito de hegemonia (HALL, 2009; APPLE, 2006).

Hegemonia é um processo cotidiano de luta por liderança e poder no qual grupos estabelecem alianças estratégicas a partir de interesses construídos como comuns. Segundo Apple (2006, p. 39): “A hegemonia atua para 'saturar' nossa própria consciência, de maneira que o mundo educacional, econômico e social que vemos e com o qual interagimos, bem como as interpretaçóes do senso comum que a ele atribuímos, se torna o mundo tout court, o único mundo". Portanto, a luta hegemônica precisa ocorrer diariamente para manter essa ligação com o mundo vivido das pessoas (HALL, 2009). A hegemonia como um processo cotidiano de saturação auxilia a compreender o argumento trazido por Ana Valeska Gomes (2015) quando afirma que, nos anos 1990, os organismos internacionais pareciam mais próximos do Brasil por terem de desenvolver esse convencimento - ou, nas palavras de Apple (2006), essa saturação - cotidiano sobre a importância das avaliaçōes para o cenário brasileiro.

Nos anos 1990, o Brasil estava consolidando um sistema de avaliação nacional e começando a fazer uso das avaliaçóes em larga escala. O Estado precisava legitimar essas avaliaçóes, demonstrando a sua importância. Apontamos aqui que, embora a influência dos organismos internacionais tenha sido menor no período após a década de 1990, os discursos veiculados por esses organismos foram importantes.

Ainda hoje esses discursos e práticas continuam sendo significativos, no sentido de asseverar que o Brasil se mantém seguindo o rumo tomado por países "desenvolvidos". O fato de países centrais ao capitalismo - como Inglaterra e Estados Unidos - já estarem realizando esse tipo de teste serviu para respaldar o que estava sendo feito no contexto brasileiro.

É importante destacar, contudo, que as políticas de avaliação, por conta do novo posicionamento do país diante dos organismos internacionais, assunto que foi abordado ao longo deste subitem, não foram rechaçadas, mas sim fortalecidas: o SAEB deixou de ser amostral e tornou-se censitário, com a criação da Prova Brasil, e houve a criação de outros testes, como a Avaliação Nacional da Alfabetização (ANA), por exemplo. Assim, defendemos que a consolidação do uso de avaliaçôes no cenário brasileiro não pode ser explicada apenas pela influência dos organismos internacionais. Afinal, se assim fosse, quando do novo posicionamento do país perante tais organismos, o Brasil poderia ter decidido não realizar mais essas avaliaçóes, o que reforça o segundo ponto defendido neste artigo: a consolidação do SAEB e das avaliaçóes em larga escala como práticas também foi 
resultado da articulação entre o que era dito internacionalmente em relação às avaliações e as particularidades do Brasil — o que será tratado no próximo tópico.

\section{Articulações em torno dos discursos e práticas globais sobre a importância dos processos avaliativos e as particularidades do Brasil}

$\mathrm{Na}$ seção anterior, apontamos o quanto a proliferação de discursos hegemônicos e de práticas concretas sobre a importância das avaliaçóes em âmbito internacional formou e forma um contexto importante para a existência das avaliaçóes em larga escala — e do Saeb, especificamente — no Brasil. Também demonstramos que a posição econômica do Estado brasileiro nos últimos 20 anos permitiu ao país um novo diálogo com os organismos mencionados, não mais necessitando de tantos empréstimos nem, portanto, precisando cumprir várias de suas exigências. No entanto, as avaliaçôes em larga escala tiveram continuidade no cenário brasileiro. Defendemos, assim, que as avaliaçóes em larga escala em nosso país, para além da influência internacional, se consolidaram também como um processo particularmente brasileiro.

Tal consolidação pode ser verificada quando grande parte dos entrevistados respondeu à questão em que eram solicitados a imaginar o que eles achavam que ocorreria no Brasil — em relação ao próprio meio educacional brasileiro, ao discurso de qualidade e à posição do Brasil no cenário internacional — caso o país decidisse que as avaliaçóes em larga escala não fossem suficientes para mensurar a qualidade da educação. Todos garantiram que não existe a possibilidade de dar "esse passo atrás", entendendo as avaliações como algo "dado". $\mathrm{Na}$ medida em que a centralidade das avaliações para as políticas educacionais se firmou como um discurso hegemônico, deixou de haver a necessidade de um reforço externo quanto a esse aspecto. Ou seja, tornou-se desnecessária uma intervenção mais direta dos organismos internacionais, contudo cabe ressaltar que essa capilarização dos discursos globais, que reforçam a importância da avaliação no território nacional, não pode ser entendida como algo do curso "natural" da história. Quando entendemos que as relações entre Estados nacionais e discursos globais — ou da globalização — são fruto de negociações, é importante pensar que houve um movimento, no próprio Estado brasileiro, que fez com que as avaliações em larga escala fossem consideradas importantes. O conceito de articulação (HALL, 2009) pode auxiliar no entendimento dessa ideia da impossibilidade de dar "esse passo atrás".

Hall (2009) afirma que o termo articulação representa uma conexão ou vínculo que não é necessariamente dado como lei ou fato da vida, requerendo condiçóes particulares. A articulação tampouco é eterna, sendo renovada 
constantemente e podendo, sob determinadas circunstâncias, desaparecer ou ser derrubada, o que leva à dissolução de antigos elos e a novas conexôes rearticulaçóes. Uma articulação pode ocorrer entre práticas distintas, o que não significa que tais práticas se tornem idênticas ou que uma dissolva a outra, cada uma permanecendo com suas determinaçóes específicas e com suas condiçóes de existência. Hall (2009) alerta que, quando uma articulação é feita, as duas práticas podem funcionar em conjunto, mas não ganham identidade imediata, permanecendo com distinçóes dentro de uma unidade. $\mathrm{O}$ autor faz um alerta sobre as articulaçôes que é importante para o entendimento do que dizem parte dos entrevistados sobre a perspectiva de que as avaliaçóes em larga escala não deixarão de existir no Brasil. Para Hall (2009), mesmo que as articulaçôes possam ser modificadas ao longo do tempo, algumas são mais rígidas e difíceis de serem desarticuladas e/ou rearticuladas. Outras, no entanto, são mais facilmente sujeitas à desarticulação. $\mathrm{O}$ caso da concepção que afirma serem as avaliações em larga escala necessárias no cenário brasileiro e que náo existe a possibilidade de elas deixarem de existir parece ser um exemplo de articulação mais firme. Mesmo havendo no início do primeiro mandato do ex-presidente Luiz Inácio Lula da Silva movimentos contrários às avaliações em larga escala, não foi possível efetuar essa particular articulação, e esses movimentos acabaram perdendo força.

Os ex-presidentes do Inep (Instituto Nacional de Estudos e Pesquisas Educacionais Anísio Teixeira), Luiz Araújo, que atuou como presidente de julho de 2003 a fevereiro de 2004, e Joaquim José Soares Neto, que atuou entre dezembro de 2009 e janeiro de 2011, afirmaram que no primeiro ano do mandato de Lula - em 2003 - houve um movimento contrário à avaliaçáo. Soares Neto (2015) relembrou uma tensa reunião que foi realizada em um auditório em Brasília na qual havia vários segmentos contrários às políticas de avaliação. Nas palavras dele, "isso foi ficando para trás, principalmente quando o ministro Fernando Haddad chegou" (SOARES NETO, 2015), destacando, assim, que a avaliação continuou tendo ênfase nos mandatos do presidente Lula (2003-2010) e no primeiro mandato da presidenta Dilma Rousseff (2011-2014). Tal ênfase pode ser percebida por meio da criação de outras avaliaçóes em larga escala (Prova Brasil, no primeiro mandato do presidente Lula, e ANA, no primeiro mandato da presidenta Dilma, por exemplo). Chico Soares, ex-presidente do INEP de fevereiro de 2014 a fevereiro de 2016, do fim do primeiro mandato do governo Dilma Rousseff até parte do segundo mandato da presidenta, afirma:

O governo Lula do ponto de vista de avaliação foi uma grande surpresa [...]. Então, em uma primeira análise a gente imagina que a avaliação de resultados ia desaparecer. E ocorreu exatamente o contrário. Inclusive, em termos financeiros. A Prova Brasil custa dez vezes mais do que o SAEB amostral (SOARES, 2015). 
Alexandre André dos Santos, diretor de Avaliação da Educação Básica/INEP de 2012 a 2014, durante o primeiro mandato da presidenta Dilma Rousseff, afirma o quanto os processos avaliativos atualmente não são mais uma pauta de discussão:

Existe uma disputa muito grande não pelo papel da avaliação em si como parte do processo, mas uma disputa de se a avaliação seria a política educacional. Esse papel da avaliação dando a centralidade da política educacional é que é um fator de disputa muito grande (SANTOS, 2015).

Essa fala evidencia a centralidade que tem tido a avaliação nos últimos anos, apontando que atualmente as disputas deixaram de ser pela existência ou não da avaliação, mas sim para decidir se ela será a política educacional central do Estado.

No entanto, isso não significa que não haja disputas em relação à avaliação. É isso que Daniel Cara (2015), coordenador geral da Campanha Nacional pelo Direito à Educação desde junho de 2006, elucida em sua fala. De acordo com ele, alguns grupos, como o Todos Pela Educação e a Fundação Lemann, são os principais vocalizadores de defesa das políticas de avaliação. Para o coordenador, a campanha coloca-se em uma posição intermediária, julgando a avaliação como importante, porém verificando a necessidade de ela ser contextualizada. As disputas existentes em torno da avaliação continuam ocorrendo - mesmo que não sejam no sentido de que ela desapareça, mas há diferentes posiçóes em relação ao uso e ao formato das avaliaçóes, por exemplo - , e para que os processos avaliativos continuem sendo entendidos como necessários se faz preciso um reforço constante, que é feito por diferentes grupos. Tais grupos compóem uma aliança fundamental em torno da avaliação. Assim, mesmo que esses grupos possuam posiçóes diferentes no tocante à avaliação em larga escala, eles estão acolhidos naquilo que Apple (2000) define como um guarda-chuva ideológico, sob o qual podem se abrigar grupos que não concordam uns com os outros totalmente, mas que possuem interesses em comum.

Sousa (2014) explica que o tipo de avaliação que vem se consolidando desde o início dos anos de 1990 no Brasil é uma avaliação em larga escala que traz marcas gerenciais. A autora aponta, contudo, que há diferentes tipos de avaliaçáo, sendo uma delas a avaliação formativa. Segundo Sousa (2014, p. 412), mesmo que essa forma de avaliação tenha sido "amplamente difundida nas redes de ensino, com expressão na legislação e documentos oficiais que tratam do tema", não houve enraizamento da avaliação formativa nas práticas escolares. A autora destaca que há muito tempo existe uma cultura de avaliação presente na escola e que as avaliações em larga escala, por restringirem a "concepção de avaliação da aprendizagem à medida de desempenho do aluno" (SOUSA, 2014, p. 412), tendem a 
ter acolhimento no contexto escolar. Com essas contribuiçóes, queremos salientar que os discursos e práticas hegemônicos não eliminam outros tipos de avaliação, para além daquelas em larga escala, no entanto o espaço para que elas sejam consideradas diminui substancialmente, conforme destacado pelos entrevistados, que afirmam quase não haver disputas relativas ao tipo de avaliação, mas sim decisões a respeito do uso dos dados gerados por elas.

Mesmo que alguns entrevistados tenham afirmado sentir que não há mais influência por parte dos organismos internacionais no período após os governos de Fernando Henrique Cardoso (1995-2002), é importante ter em conta que os discursos de tais organismos continuaram sendo importantes para balizar algumas das políticas educacionais no Brasil. Exemplos disso são:

- o próprio documento do Plano de Desenvolvimento da Educação (PDE) (BRASIL, 2008), que, ao tratar do Índice de Desenvolvimento da Educação Básica (IDEB), cita a média 6 como aquela que deve ser atingida até 2021, justificando-a por ser o nível médio de desenvolvimento da educação básica dos países integrantes da Organização para a Cooperação e Desenvolvimento Econômico (OCDE);

- a meta 7.11 do II Plano Nacional de Educação, aprovado em 2014, que tem como objetivo "melhorar o desempenho dos alunos da educação básica nas avaliaçóes da aprendizagem no Programme for International Student Assessment (PISA), tomado como instrumento externo de referência, internacionalmente reconhecido" (BRASIL, 2014, p. 63).

Ademais, muitos dos pressupostos que fundamentam a avaliação provêm de discursos que são reforçados, cotidianamente, pelos organismos internacionais no cenário global, em conferências mundiais das quais o Brasil participa. Rebeca Otero (2015), coordenadora do Setor de Educação da Organização das Nações Unidas para a Educação, a Ciência e a Cultura (Unesco) desde setembro de 2012, afirma, por exemplo, que as avaliaçóes são sempre uma pauta dos encontros entre organismos internacionais, pois há o entendimento de que os testes são importantes para todos os países. Rebeca exemplifica essa questão citando o marco de Dakar, em 2000, quando foram construídas metas internacionais, definindo as avaliaçóes como importantes. Quinze anos após Dakar, a Unesco lançou um balanço avaliando as metas do Educação para Todos e apontou como um ponto positivo o fato de que vários países já possuíam sistemas de avaliação.

A participação nas avaliaçóes internacionais demonstra que os padrões internacionais também servem como balizadores para medir a qualidade da educação. Maria Beatriz Luce (2015), ex-secretária da SEB do MEC de fevereiro de 2014 a fevereiro de 2015, último ano do primeiro mandato e início do primeiro 
ano do segundo mandato da presidenta Dilma Rousseff, aponta em sua entrevista essa participação como um sintoma do quanto as avaliações são centrais no âmbito da educação brasileira. A ex-secretária diz que participou, quando estava no MEC, de reuniôes internacionais que discutiam essas avaliaçôes e sentia que o Brasil "se posiciona nessa onda, no mainstream, no fluxo principal dessas políticas de avaliação" (LUCE, 2015). Ana Valeska Amaral Gomes, por sua vez, diz sentir que o PISA funciona como uma pauta para todos os sistemas educacionais. Embora o Brasil conte com um sistema próprio de avaliação, o resultado do PISA torna-se uma pauta de jornal e agenda parlamentar, muitas vezes ocorrendo audiência pública para discutir por que o Brasil não avançou nos resultados do teste. Cunha (2016, p. 308) corrobora a importância das avaliaçóes internacionais para o Brasil: "As comparaçóes internacionais passaram a ser pontos de referência para vários pronunciamentos de políticos oriundos de diversos partidos e de críticas feitas pela imprensa e por vários especialistas em educação pertencentes ou não às universidades".

Sobre a consolidação das avaliaçóes em larga escala no Brasil, Joaquim José Soares Neto (2015), ex-presidente do INEP, afirma em sua entrevista que existe, em certa medida, uma pauta sobre a centralidade das avaliaçóes por parte dos organismos internacionais, mas que não se pode dizer que as políticas de avaliação no Brasil são totalmente influenciadas pelos organismos internacionais. Segundo ele, houve, desde a década de 1990, um grande avanço na academia brasileira em relação aos estudos de avaliação, estabelecendo-se assim uma espécie de patrimônio brasileiro. Maria Beatriz Luce (2015) concorda que o Brasil se desenvolveu muito na área da avaliação, passando até mesmo a exportar know-how. Para elucidar essa questáo, ela usa o exemplo do INEP, um órgão governamental que atualmente recebe muitas visitas de técnicos e políticos de outros países, que vêm aprender com o exemplo brasileiro e são assistidos tecnicamente pelos funcionários do instituto. Luce (2015) afirma que o Brasil é ativo nesse relacionamento internacional na área de avaliação. Priscila Cruz, diretora executiva do Todos pela Educação, tendo auxiliado a fundar esse movimento em 2005, percebe que o Brasil está inserido em um contexto de experiência internacional, fazendo parte de um intercâmbio de ideias, citando o caso da visita de uma especialista da Finlândia. A diretora executiva conta:

Pode ser que, antes, a gente tinha uma influência mais direta com essas organizaçóes internacionais. Eu não vejo mais tanto isso, ao contrário: acho que o Brasil faz muito mais intercâmbios para conhecer experiências, acho que tem muita delegação que vai para fora para conhecer experiências exitosas. Então, eu não vejo uma interferência direta dessas organizaçóes (CRUZ, 2015). 
Essa consolidação da avaliação no Brasil também pode ser vista por meio do fortalecimento do INEP como instituição. Joaquim José Soares Neto (2015) relata que o instituto, há alguns anos, ocupava dois andares do MEC na Esplanada dos Ministérios e que, agora, possui um prédio só para si. Além disso, ele conta que o instituto náo tinha uma carreira desenhada e que, agora, a possui. O orçamento do INEP reforça seu fortalecimento ao longo dos anos: em 1995, 1,5 milhão de reais; em 2002, 170 milhóes de reais; e em 2011 de aproximadamente 500 milhóes de reais. Tais dados, mesmo que breves, apontam o crescimento que teve esse órgáo principalmente a partir de 1995, quando Fernando Henrique Cardoso assumiu a presidência (DAMASIO, 2011).

Ter clareza do fortalecimento do INEP auxilia na compreensão da centralidade que passou a ter a avaliação no cenário educacional brasileiro, tendo em vista que a instituição é o órgão responsável pela elaboração e aplicação de avaliaçóes. Paulo de Sena e Ana Valeska Amaral Gomes corroboram essa ideia ao dizerem que já há uma política de avaliação estabelecida no Brasil como certo consenso. Dessa forma, a influência dos organismos internacionais não se faz mais tão presente, já que este é um discurso que se enraizou no cenário brasileiro. Todavia, quando os entrevistados afirmam que tal influência não se faz mais presente, gera-se a impressão, mais uma vez, de que isso é pelo fato de não haver uma pauta direta em relação ao que deve ser feito no país quanto às políticas de avaliação, o que aponta um não entendimento de que tal influência foi apropriada como um discurso do nosso próprio país e, portanto, não há mais a necessidade de um convencimento externo constante. Esse processo cotidiano de convencimento dá-se muito mais no próprio cenário brasileiro, mediante disputas entre grupos com visóes distintas acerca das avaliaçôes em larga escala. Tal visão é corroborada por Maria Beatriz Luce (2015), quando garante que a avaliação em larga escala tem sido contestada. Em sua visão a "discussão não é de retirada da avaliaçấo em larga escala, mas é de colocá-la menos reificada e muito mais de mostrar os seus limites" (LUCE, 2015).

Outro fator importante para entender a consolidação das avaliaçóes em larga escala no Brasil é a ideia de que essas avaliações trazem transparência ao processo educacional, pois, por intermédio das notas, é possível saber a "qualidade" da educação de uma escola. Nos anos de 1990, o pressuposto da transparência fazia muito sentido para a sociedade em geral, na medida em que o Brasil havia vivido um período de ditadura militar (1964-1985), em que os processos não eram democráticos nem transparentes. No entanto, Maria Helena Guimarães de Castro acredita que a transparência continua tendo um lugar importante no cenário brasileiro:

Então, enfim, eu não sei o que aconteceria se, hoje, suspendessem as avaliaçóes em larga escala, eu acho que o ministro e o presidente da república teriam muitas dificuldades de jus- 
tificar. Por quê? Porque essas avaliaçóes acabaram se tornando algo muito importante nos meios de comunicaçáo, em todos os ambientes, quer dizer, tem uma grande divulgação, quer dizer, isso pode parecer falta de transparência, entendeu? Quer dizer, em um país que, hoje, está acabado pela corrupção, como é o Brasil que está um horror a vida nesse país, inflação, corrupção, tudo mais, você ainda tirar algum resultado de qualquer coisa (CASTRO, 2015).

Castro aponta na sua fala que as avaliaçóes em larga escala estão tão consolidadas no cenário brasileiro que seria difícil para um governante defender a sua retirada. $\mathrm{O}$ que a entrevistada afirma em relação à corrupção também é importante para compreender a relevância do pressuposto da transparência nos dias atuais, pois, caso um ministro ou um presidente passe a pedir pelo o fim das avaliaçóes em larga escala, ocorrerá uma espécie de defesa da não transparência dos processos educativos. É interessante destacar, todavia, que nessa fala Maria Helena Guimarães de Castro justifica a existência dessas avaliaçóes pela transparência.

Sousa (2014) traz significativas contribuiçóes para se pensar o argumento da transparência no que tange às avaliaçóes:

Sob o argumento da transparência, vêm se inserindo nos programas e planos governamentais, mecanismos que visam dar ampla visibilidade aos resultados das avaliaçóes e, em alguns casos, responsabilização de profissionais ou da escola por esses resultados, traduzida na implantação de incentivos simbólicos ou monetários, com vistas à indução de mudanças. A alocação de recursos diferenciados para as escolas, como meio de premiação por bons resultados, revela a crença de que se a competição no interior das redes de ensino induz a melhores resultados. O mesmo pressuposto está presente em iniciativas de incentivos monetários aos profissionais das escolas. A busca por melhores resultados pode levar a escola [ou, talvez, já esteja levando] a investir mais intensamente nos alunos julgados com maior potencial de obtenção de melhores pontuaçóes nas provas externas, mesmo que isso resulte em iniquidades (SOUSA, 2014, p. 413).

A autora aponta na citação que, sob o argumento da transparência, o que acaba se instalando nas escolas é um regime de competiçáo, entendido como uma forma de induzir melhores resultados.

A transparência por intermédio das avaliaçóes foi amplamente defendida nos governos de Fernando Henrique Cardoso. Exemplo disso pode ser visto no parecer da Câmara de Educação Básica do Conselho Nacional de Educação Resolução no 3, de 26 de junho de 1998 (BRASIL, 1998), que aprova as diretrizes 
curriculares nacionais para o ensino médio. Nele a relatora Guiomar Namo de Mello enfatiza a importância da divulgação dos resultados das avaliações, pois, mediante essa divulgaçáo, a sociedade em geral e, particularmente, os pais e as famílias podem participar e acompanhar as decisóes sobre objetivos, prioridades e uso de recursos (BRASIL, 1998).

O pressuposto da transparência também é utilizado quando a imprensa cria rankings com as notas que são divulgadas pelo INEP. Uma das justificativas, para que as avaliaçóes em larga escala continuem existindo é que esse tipo de teste pode ser facilmente traduzido para a população. $\mathrm{O}$ exemplo maior dessa "tradução" é o IDEB, pois por esse índice a qualidade da educação é mensurável em um número, em uma escala que pode ser facilmente compreendida por todos. Com a divulgação dessas notas, os pais, que em uma lógica gerencial passam a ser entendidos como clientes que compram o "produto" chamado educação (DRABACH; SOUZA, 2014) podem verificar se o ensino que seus filhos estão tendo nas escolas é de boa ou de má qualidade.

Cabe lembrar que Castro esteve à frente do INEP e da Secretaria Executiva do MEC nos mandatos do ex-presidente Fernando Henrique Cardoso quando pressupostos do modelo gerencial foram trazidos à cena educacional — sendo um desses pressupostos o da transparência - e as avaliações em larga escala ganharam centralidade nas açóes do Estado brasileiro na educação básica. Ao longo da entrevista concedida para o estudo em questão, foi possível perceber que, mesmo que Maria Helena Guimarães de Castro (2015) teça críticas às avaliações em larga escala, ela apresenta uma visão positiva desse tipo de instrumento avaliativo, principalmente pelos pressupostos da transparência e da accountability. Isso demonstra que há diferentes posiçóes entre os atores estatais ao longo dos governos que defendem o uso das avaliaçóes em larga escala por motivos distintos — como é possível visualizar no que se refere aos motivos pessoais que levaram o ex-presidente Luiz Inácio Lula da Silva a criar a Prova Brasil.

Chico Soares $(2015)^{4}$, ex-presidente do INEP, e Pilar Lacerda (2015), ex-secretária da SEB do MEC, afirmam em suas entrevistas que a Prova Brasil nasceu de uma vontade pessoal do então presidente Lula. Soares (2015) destacou que a história que sabe sobre a criação da Prova Brasil é que o ex-presidente Luiz Inácio Lula da Silva queria saber se cada criança, em cada escola, estava aprendendo ou não. Nas palavras de Chico Soares (2015): "Isso é muito interessante, porque, quando você pega a trajetória do presidente, ela foi uma trajetória de superação. Então, enquanto a gente fala no geral, ele fala no concreto”. O que se pode depreender da fala do ex-presidente do INEP é que ele entende que a necessidade de avaliar a qualidade do ensino que é ofertado a cada criança nasceu da demanda que o ex-presidente Lula tinha de saber o que estava ocorrendo de forma concreta com cada aluno de todas as escolas do Brasil. Contudo, essa vontade pessoal não poderia ter sido concretizada caso não houvesse um cenário favorável 
às avaliaçóes em larga escala, cujos processos avaliativos já eram hegemônicos no contexto internacional e estavam sendo consolidados no Brasil. Portanto, mesmo que a criação da Prova Brasil tenha nascido da vontade do ex-presidente Lula e que isso mereça destaque, tal fato precisa ser lido em seus contextos nacional e global.

Pilar Lacerda (2015) afirmou que o ex-ministro Fernando Haddad contava a história que o ex-presidente Lula chamou Tarso Genro, quando à frente do Ministério da Educação, e disse que desejava realizar uma prova para ver como cada criança estava aprendendo. A ex-secretária afirmou que o INEP se debruçou sobre essa demanda e fez o desenho da Prova Brasil. Segundo ela, o ex-presidente havia solicitado que a prova fosse feita desde a $2^{\mathrm{a}}$ até a $8^{\mathrm{a}}$ série (isso ainda quando do ensino fundamental de oito anos), no entanto Pilar Lacerda (2015) destaca que isso era totalmente inviável, tanto em termos de logística quanto financeiramente falando.

Pelo que afirmam Chico Soares (2015) e Pilar Lacerda (2015), o objetivo inicial do ex-presidente Lula era, com essa prova, verificar se toda e qualquer criança que frequentava uma escola no Brasil estava de fato aprendendo. Chico Soares até mesmo, em sua fala, trata em certa medida desse ponto ao afirmar que nas gestóes de Luiz Inácio Lula da Silva "você teve com muita mais ênfase esta dimensão: 'Olha, eu estou fazendo avaliação não é para prestação de contas, eu estou fazendo avaliação porque eu preciso saber quem teve o direito à educação atendido"' (SOARES, 2015).

Para o ex-presidente do INEP, o pressuposto de accountability era muito mais presente durante as gestóes do ex-presidente Fernando Henrique Cardoso. Essa fala de Chico Soares (2015) corrobora a análise que realizamos de uma fala de Maria Helena Guimarães de Castro (2015), que foi presidente do INEP e secretária executiva do MEC ao longo dos mandatos do ex-presidente Fernando Henrique Cardoso, em que ela defende a existência das avaliaçóes em larga escala em função da transparência que esse tipo de instrumento avaliativo traz para o cenário educacional. Essa defesa de Castro aproxima-se da análise de Chico Soares da presença da accountability nos governos FHC e se distancia daquele que, segundo os entrevistados, foi o motivo pelo qual o ex-presidente Lula criou a Prova Brasil, ou seja, saber se os alunos estáo efetivamente aprendendo o que é ensinado nas escolas.

No entanto, mesmo que este fosse de fato o objetivo inicial do ex-presidente Lula, é importante ter em conta que políticas posteriores como o PDE e o IDEB favoreceram o uso dos dados da Prova Brasil para a realização de rankings, para a responsabilização das escolas e dos docentes pelos resultados das instituiçôes escolares e para o estabelecimento de competição.

Ainda em relação às diferenças presentes ao longo dos governos no que tange aos princípios que fundamentaram a avaliação em larga escala, é 
importante salientar que o PDE informa que o escopo de atendimento prioritário é o dos municípios e escolas com os mais baixos indicadores, abrangendo, no curto prazo, todos que estejam abaixo da média nacional (BRASIL, 2008). Este é um aspecto importante: as escolas que passaram a ser auxiliadas, a partir do IDEB, foram aquelas que tinham os índices mais baixos e não os mais altos, o que diferencia essa política daquelas de caráter neoliberal, em que escolas com menores notas nos testes eram punidas ou, muitas vezes, fechadas (AFONSO, 2009; FREITAS, 2012; GUISBOND; NEILL; SCHAEFFER, 2012). No documento do PDE, há a explicação do porquê não punir as escolas com menores IDEB:

Outro equívoco comum é a defesa de um sistema de incentivos composto de prêmios e puniçóes, em geral de caráter pecuniário, às escolas ou às redes educacionais que cumprirem ou não metas de qualidade, em geral preestabelecidas. Esta perspectiva desconsidera o fato de que restringir o financiamento de escolas ou sistemas educacionais por queda de desempenho pode significar punir uma segunda vez aquele que já não viu respeitado seu direito de aprender - o educando (BRASIL, 2008, p. 22).

Ao tomar a centralidade da avaliação, a criação de um índice que tem como objetivo a responsabilização das escolas e das comunidades, poderia se esperar que o próximo passo, em uma lógica neoliberal e/ou gerencial, seria a punição das escolas com menores notas, detectadas, assim, como as menos eficientes e qualificadas na prestação de serviço, no entanto é o contrário que ocorre. Isso no PDE pode ser lido conforme uma perspectiva de justiça social e da busca por mais igualdade no sistema de educação, quando é afirmado no documento - como mostrado no trecho exposto - que a punição poderia significar prejudicar uma segunda vez quem já não viu respeitado o seu direito de aprender: "A razão de ser do PDE está precisamente na necessidade de enfrentar estruturalmente a desigualdade de oportunidades educacionais" (BRASIL, 2008, p. 5).

A política de repasse de verbas para as escolas com piores notas no IDEB demonstra uma articulaçáo (HALL, 2009) no que se refere às ações do Estado na educação básica, entre diferentes aspectos: ao mesmo tempo em que há ênfase na mensuração da qualidade por meio do IDEB e na busca de eficiência - aspectos relacionados aos pressupostos gerenciais — , há também apoio às escolas com menores notas, o que, segundo o próprio documento do PDE (BRASIL, 2008), se dá para não prejudicar uma segunda vez quem já não viu respeitado o seu direito de aprender e para enfrentar estruturalmente a desigualdade de oportunidades educacionais. Por meio do envio de verbas para as escolas com menor IDEB, pode-se perceber que as açôes do Estado na educação podem 
ser aproximadas de uma ideia de bem-estar social, isto é, o âmbito estatal provendo melhorias nas condições das escolas. Logo, não há total descentralização das responsabilidades para as escolas, uma vez que o Estado ainda chama para si, por uma política de caráter redistributivo, a responsabilidade de auxiliar as instituiçóes escolares. Mesmo assim, essa ação ainda tem marcas gerenciais, já que o repasse de verbas para as instituiçóes escolares inclui um caráter descentralizador, no qual as escolas precisam gerir os seus recursos e melhorar sua gestão em busca de maior eficiência e, por conseguinte, melhores notas no IDEB. Ademais, a ideia de qualidade na educação continua vinculada ao entendimento da educação como algo mensurável. Portanto, mesmo que as avaliaçóes em larga escala tenham permanecido ao longo do período de 1995-2014, é possível perceber diferentes matizes em relação aos processos avaliativos.

Mesmo que nosso objetivo, neste texto, não seja abordar os tipos de avaliação, mas, sim, apontar a consolidação das avaliações em larga escala no Brasil, é importante salientar que há distintas posiçóes dos sujeitos entrevistados em relação às avaliações. É possível perceber que os representantes de organizações não estatais (como é o caso de Cláudia Costin, representando o Banco Mundial, de Rebeca Otero, representante da Unesco — ambos órgãos supraestatais - e de Priscila Cruz, do movimento Todos pela Educação) se aproximam mais das posiçóes dos entrevistados que atuaram como formuladores de política nos governos Fernando Henrique Cardoso. Cabe ressaltar que foi durante os mandatos desse presidente que as avaliaçôes em larga escala passaram a ser enfatizadas (FREITAS, 2004; PERONI, 2003). Portanto, é possível depreender que naquele momento histórico as posiçóes dos sujeitos que faziam parte do governo foram fundamentais para a consolidação de um cenário favorável às avaliaçóes em larga escala. Segundo a literatura que trata especificamente das avaliaçóes em larga escala no Brasil (FREITAS, 2004; BONAMINO; SOUSA, 2012; SOUZA; OLIVEIRA, 2003; COELHO, 2008), o tipo de avaliação que se fez presente desde o primeiro mandato de Fernando Henrique Cardoso traz em si muitas marcas gerenciais, e isso tem repercussóes para a noção de qualidade, pois "sempre que tratamos do tema avaliação educacional, necessariamente, à abordagem assumida está subjacente uma dada concepção de qualidade, assim, não há neutralidade nos caminhos utilizados em uma atividade avaliativa" (SOUSA, 2014, p. 408).

Ao finalizar esta seção, é possível afirmar que, depois de 2003, o Brasil possui outra relação com os organismos internacionais, o que foi justificado especialmente por intermédio de dois pontos:

- a não necessidade de contar tanto com empréstimos na área da educação fez com que o país não precisasse mais cumprir várias determinaçóes e exigências de organismos internacionais; 
- pela importância de as avaliaçóes terem sido assimiladas no Brasil, como algo fundamental e central na educação, não é mais preciso que haja reforço constante de tais organismos sobre a necessidade de o país contar com avaliaçóes.

Como já abordado no início deste artigo, uma das formas de propagação das ideias envolvidas nos processos de globalização foi a partir dos organismos internacionais. Tais organismos foram importantes na construção de uma ideia hegemônica da centralidade das avaliações e da constituição, em diferentes países, de sistemas nacionais de avaliação.

\section{Considerações finais}

Neste artigo examinamos o estabelecimento das avaliações em larga escala no cenário brasileiro por meio dos discursos de alguns atores centrais a esse processo. Esses discursos documentam um processo de consolidação da hegemonia em torno das avaliaçóes nacionais no Brasil. Como defendemos ao longo do texto, um processo hegemônico náo representa o esgotamento das posiçóes e visóes alternativas, mas implica relegá-las a vozes periféricas, com pouca visibilidade. A construção da hegemonia satura os discursos e as práticas com as posiçôes dominantes a ponto de produzir a sensação de não haver alternativas viáveis. O exemplo das avaliaçóes nacionais no Brasil pode, como demonstramos no texto, ser entendido por meio dessa consolidação hegemônica, que, de resto, não está restrita ao âmbito nacional, mas se constitui como discurso e prática global. Se ficou claro que não há transposição ou direta determinação dos órgãos supranacionais no Brasil ou de instituições ou fundaçóes nacionais, também foi possível documentar que a consolidação das avaliaçôes de larga escala no Brasil se deu em um contexto global/local em que discursos e práticas hegemônicos limitavam o campo das possibilidades.

Mostramos também que o processo de construção de hegemonia está sempre constituído de articulaçôes, não necessárias e mais ou menos estáveis. Posiçôes como a garantia da qualidade da educação, verificada por processos avaliativos censitários, são articuladas a noçoóes gerenciais de accountability e controle do trabalho docente e compóem a particular configuração que garante o avanço da centralidade das avaliaçôes em larga escala no Brasil, algo que fica nítido nos discursos dos atores centrais entrevistados.

Pensamos que o uso de lentes teóricas como as que utilizamos permitem capturar a complexidade sempre presente em processos sociais. Focando também nas contradições presentes nas formaçóes hegemônicas e nas articulaçốes sempre 
em risco de serem rompidas, podemos vislumbrar a possibilidade da construçáo de des/rearticulações e contra-hegemonia.

\section{Notas}

1. Em linhas gerais, o assunto principal nesse tipo de entrevista é a própria teoria construída pelo pesquisador, e a entrevista é realizada para "confirmar, falsificar e, acima de tudo, para refinar essa teoria” (PAWSON; TILLEY, 2000, p. 155). Assim, o ponto-chave da entrevista realista é a estratégia de refinamento conceitual (PAWSON; TILLEY, 2000). O pesquisador realiza perguntas em que explicita a sua teoria, dando a oportunidade de os entrevistados explicarem e esclarecerem seu pensamento, confirmando à teoria do pesquisador ou contrapondo-se a ela.

2. Grant pode ser traduzido por subvenção.

3. O nome completo da entrevistada é Maria do Pilar Lacerda, no entanto usamos aqui o nome pelo qual ela é conhecida no meio político, que é Pilar Lacerda.

4. O nome completo do entrevistado é José Francisco Soares, no entanto usamos aqui o nome pelo qual ele é conhecido no meio político, que é Chico Soares.

\section{Referências}

AFONSO, A. J. Nem tudo o que conta em educação é mensurável ou comparável. Crítica à accountability baseada em testes estandardizados e rankings escolares. Revista Lusófona de Educaçáo, Lisboa, v. 13, n. 13, p. 13-29, 2009.

APPLE, M. W. Ideologia e Currículo. Tradução de Vinicius Figueira. 3. ed. Porto Alegre: Artmed, 2006.

APPLE, M. W. Política Cultural e Educação. Tradução de José do Amaral Ferreira. São Paulo: Cortez, 2000.

BONAMINO, A.; FRANCO, C. Avaliaçáo e Política Educacional: o processo de institucionalização do SAEB. Cadernos de Pesquisa, n. 108, p. 101-132, 1999. http:// dx.doi.org/10.1590/S0100-15741999000300005

BONAMINO, A.; SOUSA, S. Z. Três geraçôes de avaliação da educação básica no Brasil: interfaces com o currículo da/na escola. Educaçáo e Pesquisa, São Paulo, v. 38, n. 2, p. 373-388, abr./jun. 2012. http://dx.doi.org/10.1590/S1517-97022012005000006

BRASIL. Ministério da Administração e Reforma do Estado. Plano Diretor da Reforma do Aparelho do Estado. Brasília: Ministério da Administração e Reforma do Estado, 1995.

BRASIL. Ministério da Educação. O Plano de Desenvolvimento da Educaçáo: razóes, princípios e programas. Brasília: Instituto Nacional de Estudos e Pesquisas Educacionais Anísio Teixeira, 2008. 
BRASIL. Plano Nacional de Educaçáo 2014-2024: Lei no 13.005, de 25 de junho de 2014, que aprova o Plano Nacional de Educação (PNE) e dá outras providências. Brasília: Câmara dos Deputados, Ediçôes Câmara, 2014.

BRASIL. Resolução CNE/CEB n.o 3, de 26 de junho de 1998. Institui as Diretrizes Curriculares Nacionais para o Ensino Médio. Conselho Nacional de Educação. Brasília, 1998.

CASTRO, Maria Helena Guimarães de. Maria Helena Guimarães de Castro: entrevista concedida para a tese de doutorado intitulada "As açóes do Estado brasileiro na educação básica: uma análise a partir do Sistema de Avaliação da Educação Básica" [2015]. Porto Alegre, 2015. Entrevistador: Iana Gomes de Lima.

COELHO, M. I. de M. Vinte anos de avaliação da educação básica no Brasil: aprendizagens e desafios. Ensaio: Avaliaçáo e Políticas Públicas em Educaçáo, Rio de Janeiro, v. 16, n. 59, p. 229-258, abr./jun. 2008. http://dx.doi.org/10.1590/S0104-40362008000200005

CUNHA, C. da (coord.). O MEC pós-Constituiçáo. Brasília: Líber Livro, 2016.

DAMASIO, L. Desenvolvimento Institucional do Inep. 2011. Dissertação (Mestrado em Administração) - Escola de Administração de Empresas de São Paulo, São Paulo, 2011.

DRABACH, N. P.; SOUZA, Â. R. de. Leituras sobre a gestão democrática e o "gerencialismo" na/da educação no Brasil. Revista Pedagógica, v. 16, n. 33, p. 221-248, jul./dez. 2014.

FONSECA, M. A experiência de cooperação entre o Brasil e o Banco Mundial: redefinindo o papel da educação e do professor. Linhas Críticas, Brasília, v. 7, n. 12, p. 85-97, jan./ jun. 2001.

FONSECA, M. O Banco Mundial como referência para a justiça social no terceiro mundo: evidências do caso brasileiro. Revista da Faculdade de Educação, São Paulo, v. 24, n. 1, p. 37-69, jan./jun. 1998. http://dx.doi.org/10.1590/S0102-25551998000100004

FREITAS, D. N. T. de. Avaliação da educação básica e ação normativa federal. Cadernos de Pesquisa, v. 34, n. 123, p. 663-689, set./dez. 2004. http://dx.doi.org/10.1590/S010015742004000300008

FREITAS, L. C. Os reformadores empresariais da educação: da desmoralização do magistério à destruição do sistema público de educação. Educaçáo e Sociedade, Campinas, v. 33, n. 119, p. 379-404, abr./jun. 2012. http://dx.doi.org/10.1590/S0101$\underline{73302012000200004}$

GOMES, Ana Valeska Amaral. Ana Valeska Amaral Gomes: entrevista concedida para a tese de doutorado intitulada "As açóes do Estado brasileiro na educação básica: uma análise a partir do Sistema de Avaliação da Educação Básica” [2015]. Brasília, 2015. Entrevistador: Iana Gomes de Lima.

GUISBOND, L.; NEILL, M.; SCHAEFFER, B. A década de progresso educativo perdida sob a NCLB: que liçóes tirar desse fracasso político? Educaçáo e Sociedade, Campinas, v. 33, n. 119, p. 405-430, abr./jun. 2012. 
HALL, S. Da diáspora: identidades e mediaçóes culturais. Belo Horizonte: Editora da UFMG, 2009.

HADDAD, S. Introdução. In: HADDAD, S. et al. (orgs.). Banco Mundial, OMC e FMI: o impacto nas políticas educacionais. São Paulo: Cortez, 2008.

LACERDA, Pilar. Pilar Lacerda: entrevista concedida para a tese de doutorado intitulada "As açóes do Estado brasileiro na educação básica: uma análise a partir do Sistema de Avaliação da Educação Básica" [2015]. São Paulo, 2015. Entrevistador: Iana Gomes de Lima.

LUCE, Maria Beatriz. Maria Beatriz Luce: entrevista concedida para a tese de doutorado intitulada "As açôes do Estado brasileiro na educação básica: uma análise a partir do Sistema de Avaliação da Educação Básica” [2015]. Porto Alegre, 2015. Entrevistador: Iana Gomes de Lima.

PAWSON, R.; TILLEY, N. Realistic Evaluation. Londres: Sage Publications, 2000.

PERONI, V. Política Educacional e Papel do Estado: no Brasil dos anos 1990. São Paulo: Xamã, 2003.

POCHMANN, M. Políticas públicas e situação social na primeira década do século XXI. In: SADER, E. (org.). 10 anos de governos pós-neoliberais no Brasil: Lula e Dilma. São Paulo: Boitempo; Rio de Janeiro: FLACSO, 2013. p. 145-156.

SADER, E.; GENTILI, P. O necessário, o possível e o impossível: Luiz Inácio Lula da Silva, entrevista concedida a Emir Sader e Pablo Gentili. In: SADER, E. (org.). 10 anos de governos pós-neoliberais no Brasil: Lula e Dilma. São Paulo: Boitempo; Rio de Janeiro: FLACSO, 2013. p. 9-30.

SANTOS, R. L. L. dos. Sistema Nacional de Avaliação da Educaçáo Básica: situando olhares, construindo perspectivas. 2007. Tese (Doutorado) - Pontifícia Universidade Católica de São Paulo, São Paulo, 2007.

SENA, Paulo de. Paulo de Sena: entrevista concedida para a tese de doutorado intitulada "As açôes do Estado brasileiro na educação básica: uma análise a partir do Sistema de Avaliação da Educação Básica” [2015]. Brasília, 2015. Entrevistador: Iana Gomes de Lima.

SILVA, C. C.; AZZI, D.; BOCK, R. Banco Mundial em foco: sua atuação na educação brasileira e na dos países que integram a Iniciativa Via Rápida na América Latina. In: HADDAD, S. et al. (orgs.). Banco Mundial, OMC e FMI: o impacto nas políticas educacionais. São Paulo: Cortez, 2008.

SILVA, L. I. L. da. Pronunciamento à nação do Presidente da República em cadeia de rádio e TV, sobre o pagamento da dívida com o FMI. Brasília, 16 jan. 2006.

SOARES, José Francisco. José Francisco Soares: entrevista concedida para a tese de doutorado intitulada "As açôes do Estado brasileiro na educação básica: uma análise a partir do Sistema de Avaliação da Educação Básica” [2015]. Brasília, 2015. Entrevistador: Iana Gomes de Lima. 
SOUSA, S. Z. Concepções de qualidade da educação básica forjadas por meio de avaliaçóes em larga escala. Avaliaçáo, Campinas; Sorocaba, v. 19, n. 2, p. 407-420, jul. 2014. http:// dx.doi.org/10.1590/S1414-40772014000200008

SOUZA, S. Z. L. de; OLIVEIRA, R. P. de. Políticas de Avaliação da Educação e Quase Mercado no Brasil. Educaçáo e Sociedade, Campinas, v. 24, n. 84, p. 873-895, set. 2003. http://dx.doi.org/10.1590/S0101-73302003000300007

TUDE, J. M.; MILANI, C. S. A Política Externa Brasileira em relação ao Fundo Monetário Internacional durante o Governo Lula. Revista Brasileira de Política Internacional, Brasília, v. 56, n. 1, p. 85-103, 2013. http://dx.doi.org/10.1590/S0034$\underline{73292013000100005}$

\section{SOBRE OS AUTORES}

Iana Gomes de Lima tem pós-doutorado pela Universidade Federal de Pelotas (UFPel). Professora adjunta da Faculdade de Educação da Universidade Federal do Rio Grande do Sul (UFRGS).

Luís Armando Gandin é doutor em Curriculum and Instruction pela University of Wisconsin-Madison. Professor titular da Faculdade de Educaçáo e do Programa de PósGraduação em Educação da Universidade Federal do Rio Grande do Sul (UFRGS) e Bolsista de Produtividade do CNPq.

Recebido em 18 de junho de 2018.

Aceito em 20 de setembro de 2018. 